\title{
Hypoxia-Inducible Factor 1 Alpha Is Dispensable for Host Defense of Group B Streptococcus Colonization and Infection
}

\author{
Gregory R. Lum ${ }^{\mathrm{a}}$ Vicki Mercado ${ }^{\mathrm{b}}$ Diede van Ens ${ }^{\mathrm{a}}$ Victor Nizet ${ }^{\mathrm{a}, \mathrm{c}}$ \\ Jacqueline M. Kimmey ${ }^{a, d}$ Kathryn A. Patras ${ }^{a, b}$, e \\ aDivision of Host-Microbe Systems \& Therapeutics, Department of Pediatrics, UC San Diego, La Jolla, CA, USA; \\ ${ }^{b}$ Department of Molecular Virology and Microbiology, Baylor College of Medicine, Houston, TX, USA; 'Skaggs School \\ of Pharmacy and Pharmaceutical Sciences, UC San Diego, La Jolla, CA, USA; dDepartment of Microbiology and \\ Environmental Toxicology, UC Santa Cruz, Santa Cruz, CA, USA; ${ }^{A}$ Alkek Center for Metagenomics and Microbiome \\ Research, Baylor College of Medicine, Houston, TX, USA
}

\section{Keywords}

Group B streptococcus · Hypoxia-inducible factor 1 alpha . Vaginal colonization · Innate immunity $\cdot$ Macrophage

\begin{abstract}
Group B Streptococcus (GBS) is a leading cause of neonatal morbidity and mortality, and the primary source of exposure is the maternal vagina. Intrapartum antibiotic prophylaxis for GBS-positive mothers has reduced the incidence of GBS early-onset disease, however, potential long-lasting influence of an antibiotic-altered neonatal microbiota, and the frequent clinical sequelae in survivors of invasive GBS infection, compels alternative treatment options for GBS. Here, we examined the role of transcription factor hypoxia-inducible factor 1 alpha (HIF-1a), widely recognized as a regulator of immune activation during infection, in the host response to GBS. Given the importance of endogenous HIF-1a for innate immune defense, and the potential utility of HIF-1 a stabilization in promoting bacterial clearance, we hypothesized
\end{abstract}

karger@karger.com www.karger.com/jin

Karger"

BOPEN ACCESS
(C) 2021 The Author(s)

Published by S. Karger AG, Basel

This is an Open Access article licensed under the Creative Commons Attribution-NonCommercial-4.0 International License (CC BY-NC) (http://www.karger.com/Services/OpenAccessLicense), applicable to the online version of the article only. Usage and distribution for commercial purposes requires written permission. that HIF-1 a could play an important role in coordinating host responses to GBS in colonization and systemic disease. Counter to our hypothesis, we found that GBS infection did not induce HIF-1a expression in vaginal epithelial cells or murine macrophages, nor did HIF-1a deficiency alter GBS colonization or pathogenesis in vivo. Furthermore, pharmacological enhancement of HIF-1 a did not improve control of GBS in pathogenesis and colonization models, while displaying inhibitory effects in vaginal epithelial cytokines and immune cell killing in vitro. Taken together, we conclude that HIF-1a is not a prominent aspect of the host response to GBS colonization or invasive disease, and its pharmacological modulation is unlikely to provide significant benefit against this important neonatal pathogen.

(c) 2021 The Author(s).

Published by S. Karger AG, Basel

Gregory R. Lum and Vicki Mercado contributed equally to this work.
Correspondence to:

Kathryn A. Patras, kathryn.patras@bcm.edu 


\section{Introduction}

Group B Streptococcus (GBS or Streptococcus agalactiae) is associated with as many as 409,000 clinical infections every year globally [1], and remains a leading cause of maternal and fetal morbidity and mortality. Conservative approximations attribute 147,000 stillbirths and infant deaths to GBS annually [1]. Considered a "pathobiont," GBS is part of the normal gastrointestinal and vaginal microbiota in many healthy women, colonizing up to $21-30 \%$ in pregnancy [2]. During the second or third trimester, GBS can ascend from the vaginal tract and spread to the fetus in utero; alternatively, it may be transmitted to neonates during vaginal delivery [3]. Maternal GBS colonization and/or infection increase the risk of premature delivery and neonatal sepsis. In the infant, early-onset GBS disease, defined as occurring in the first 1-7 days of life, manifests most often as pneumonia and sepsis. Late-onset disease, occurring between 7 and 90 days of life, most commonly presents sub-acutely with a high risk of meningitis, and can also present as soft tissue infection [4]. Even among infants who survive GBS meningitis, approximately $32-44 \%$ develop long-term neurological and cognitive impairments such as global developmental delay, bilateral sensorineural deafness, or persistent seizure disorder $[5,6]$. Current intrapartum antibiotic prophylaxis for GBS-positive mothers has markedly reduced incidence of GBS early-onset disease, yet comes with secondary consequences on the neonatal microbiome, such as decreased abundance of beneficial commensals [7]. Furthermore, rates of GBS late-onset disease have not diminished [2]. The potential long-lasting impact of an altered neonatal microbiota on health and development, and the sequelae imposed by GBS infection, call for alternative treatment options for GBS [8]. One appealing alternative strategy to antibiotic therapy would be to enhance the endogenous host immune response against GBS.

Neonatal defenses against GBS are primarily driven by innate immunity as the adaptive immune system is not yet fully developed. Upon host recognition of GBS through toll-like receptors (TLRs) 2 and 6, and through complement molecules deposited on the bacterial surface, innate immune cells produce many cytokines such as IL- $1 \beta$, IL-6, IL- 8 , IL- 12 , TNF- $\alpha$, IFN- $\beta$, and IFN- $\gamma$, to promote GBS phagocytic clearance and containment [912]. While all of these cytokines contribute to anti-GBS defense, IL- 8 and IL- $1 \beta$ are especially critical. IL- 8 promotes neutrophil migration and activation, and IL- $1 \beta$ signaling, a driver of immune cell proliferation, differen- tiation and activation, is indispensable for protection against GBS infection in animal models $[9,12-14]$. The clinical relevance of these cytokines is supported by higher maternal plasma IL- $1 \beta$ in early term births and GBS neonatal infections, and IL- 8 has been validated as an early diagnostic marker for neonatal sepsis $[15,16]$. In addition to neonatal innate immune responses, maternal vaginal responses to GBS are key to limiting maternal colonization, infection, and transmission during delivery. Vaginal epithelial cells and whole vaginal tissue directly respond to GBS colonization and infection by producing an abundance of pro-inflammatory signals: IL- $1 \beta$ IL-6, IL-8, CXCL1, TNFa, and GM-CSF [2, 17-19]. Of note, the vaginal and cervical epithelium of healthy women produces high levels of IL- $1 \beta$ and IL- 8 during and throughout pregnancy [20]. These parallel cellular responses to GBS in colonization and invasive disease suggest that pharmacological boosting of host immune signaling pathways may confer protection against GBS in prophylactic and therapeutic contexts.

Recently, transcription factors associated with the cellular response to hypoxia have been identified as important immune regulators in bacterial pathogenesis. Hypoxia-inducible factor 1 alpha (HIF-1 $\alpha$ ) participates in a heterodimeric complex (HIF) as a master regulator of cell adaptation to hypoxic conditions by driving expression of genes involved in metabolism, vascularization, and immune activation [21]. During normoxia, HIF-1 $\alpha$ also regulates immune cell behavior, differentiation, and effector genes such as IL- 8, IL- $1 \beta$, TNF $\alpha$, iNOS, and cathelicidin [22-28]. Bacterial components such as LPS directly increase HIF-1 $\alpha$ expression in host immune cells as an added measure of host defense [29, 30]. HIF-1 $\alpha$ deficiency in macrophages and neutrophils leads to impaired ATP generation, intracellular killing and effector function (i.e., cytokine and antimicrobial peptide production) against group A Streptococcus and Pseudomonas aeruginosa [25, 31]. Furthermore, epithelial HIF-1 $\alpha$ deficiency reduces host control of uropathogenic E. coli or group A Streptococcus in the bladder and skin, respectively, [32, 33]. Stabilization of HIF-1 $\alpha$ with AKB-4924, a pharmacologic inhibitor of HIF-1 $\alpha$ degradation, decreases uropathogenic E. coli urinary tract colonization and infection in mice [32], and increases phagocytic clearance of methicillinresistant Staphylococcus aureus in vitro and in vivo [34]. Given the importance of endogenous HIF-1a on innate immune activity, and success of HIF-1a stabilization in other models of bacterial pathogenesis, we hypothesized that HIF-1a could play an important role in coordinating host responses to GBS, and that pharmacological stabili- 
zation of HIF-1 a may improve host control of GBS colonization and infection.

The contribution of HIF-1a to host interactions with GBS was investigated in models of both colonization and systemic disease. Additionally, we tested the effects of pharmacological enhancement of HIF-1a in these same models. Counter to our hypothesis, we found that GBS infection did not induce HIF-1a expression in vaginal epithelial cells or murine macrophages, nor did HIF-1a deficiency alter GBS colonization or pathogenesis in vivo. Furthermore, pharmacological enhancement of HIF-1a did not improve control of GBS in pathogenesis and colonization models, while displaying inhibitory effects on vaginal epithelial cytokine production and immune cell killing in vitro. Taken together, we conclude that HIF-1a is not a prominent aspect of the host response to GBS colonization or invasive disease, and its pharmacological modulation is unlikely to provide significant benefit against this important neonatal pathogen.

\section{Materials and Methods}

\section{Reagents}

AKB-4924 was acquired from Aerpio Therapeutics (Cincinnati, $\mathrm{OH}, \mathrm{USA}$ ) at a concentration of $4 \mathrm{mg} / \mathrm{mL}$ dissolved in $12 \%$ 2-hydroxypropyl-beta-cyclodextrin (HP $\beta \mathrm{CD}$ ) at a $\mathrm{pH}$ of $4.0 .12 \%$ $\mathrm{HP} \beta \mathrm{CD}$ at $\mathrm{pH} 4.0$ was used as a vehicle control. Phorbol 12-myristate 13-acetate (PMA) was acquired from Sigma Aldrich and diluted to a working concentration of $25 \mathrm{nM}$ in Hanks' Balanced Salt Solution. Hanks' Balanced Salt Solution was used as a vehicle control.

\section{Bacterial Strains and Growth Conditions}

GBS strains COH1 (ATCC BAA-1176), isogenic $\beta$-hemolysin deficient mutant $(\Delta c y l E)$ [35], and A909 (ATCC BAA-1138), were grown to stationary phase at $37^{\circ} \mathrm{C}$ in Todd-Hewitt broth (Hardy Diagnostics) for at least $16 \mathrm{~h}$. Cultures were diluted in fresh ToddHewitt broth and incubated at $37^{\circ} \mathrm{C}$ until mid-logarithmic phase (defined as $\left.\mathrm{OD}_{600}=0.4\right)$. Bacterial cultures were centrifuged $(3,220$ $g, 5 \mathrm{~min}$ ), washed in sterile PBS, and resuspended at the desired concentration in RPMI-1640 (in vitro) or sterile PBS (in vivo). For opsonization experiments, GBS was resuspended in RPMI-1640 (Gibco) containing 2\% FBS $+20 \%$ pooled human serum for $10 \mathrm{~min}$ before infection. Pooled human serum was obtained from peripheral blood from $>10$ healthy adult donors as approved by UC San Diego Human Research Protection Program Institutional Review Board IRB\# 131002. Inoculum was quantified by plating serial dilutions on Todd-Hewitt agar (THA) plates and counting the colony-forming units (CFUs).

\section{Human and Murine Cell Lines}

Immortalized human vaginal epithelial cells (VK2/E6E7) and murine macrophage cell line (RAW 264.7) were acquired from the American Type Culture Collection (ATCC CRL-2616 and ATCC TIB-71, respectively). VK2 cells were cultured in keratinocyte se- rum-free medium (KSFM) (Gibco) with $0.5 \mathrm{ng} / \mathrm{mL}$ human recombinant epidermal growth factor and $0.05 \mathrm{mg} / \mathrm{mL}$ bovine pituitary extract. RAW 264.7 cells were grown in Dulbecco's Modified Eagle Medium $(G i b c o)+10 \%$ FBS (heat inactivated). Cells were cultured in a $37^{\circ} \mathrm{C}$ incubator with $5 \% \mathrm{CO}_{2}$. Cells were split every 3-4 days at $\sim 80 \%$ confluency, and $0.25 \%$ trypsin/2.21 mM EDTA (Corning) or cell scrapers were used to detach VK2 and RAW 264.7 cells for passaging, respectively.

\section{VK2-HRE and RAW-HRE Reporter Cell Generation}

VK2 and RAW 264.7 HIF-1a reporter cells were generated using previously published methods [36]. Cell lines (70\% confluency, 24-well plates) were transduced at a multiplicity of infection $(\mathrm{MOI})=20$ using the Cignal Lenti Reporter mCMV-HREluciferase (CLS-007L) and Cignal Lenti control vector mCMVluciferase (CLS-NCL) (both viral preparations were purchased from Qiagen). The cells were also treated with SureENTRY Transduction Reagent (Qiagen) at $8 \mu \mathrm{g} / \mathrm{mL}$ in the presence of normal culture media supplemented with $1 \times$ MEM Non-Essential Amino Acids (Gibco) during transduction. After $24 \mathrm{~h}$, the lentiviral supernatant was removed and replaced with normal culture media supplemented with MEM Non-Essential Amino Acids. Cells were selected after $48 \mathrm{~h}$ for puromycin (Gibco) resistance at a concentration of $2.5 \mu \mathrm{g} / \mathrm{mL}$ (VK2) or $20 \mu \mathrm{g} / \mathrm{mL}$ (RAW 264.7). Cells were maintained in puromycin online suppl. media (for all online suppl. material, see www.karger.com/ doi/10.1159/000515739).

\section{HRE-Luciferase Assays}

VK2-HRE and RAW-HRE cells were plated the day before in white opaque, tissue culture 96 well plates in culture media as described above. Cells were pretreated with $12 \mu \mathrm{g} / \mathrm{mL}$ AKB-4924 or vehicle for $4 \mathrm{~h}$ before infection. Cells were infected with GBS $\mathrm{COH} 1$ or isogenic $\Delta c y l E$ at $\mathrm{MOI}=20$ as indicated in figure legends. At $2 \mathrm{~h}$ postinfection, cells were washed once with PBS and lysed with $25 \mu \mathrm{L} /$ well of Steady-Glo ${ }^{\circledR}$ Luciferase Assay System reagent (Promega) for $5 \mathrm{~min}$ at room temp. RPMI-1640, containing no phenol red, was added ( $25 \mu \mathrm{L} /$ well $)$, mixed, incubated at room temperature for $15 \mathrm{~min}$, and luminescence was then measured on an EnSpire Alpha Multimode Plate Reader (PerkinElmer). Arbitrary units of luminescence were normalized across individual experiments using values from vehicle-treated, uninfected VK2HRE or RAW-HRE cells.

\section{VK2 Adherence Assay}

Vaginal epithelial adherence assays were performed as adapted from prior methods $[37,38]$. VK2 cells were plated to confluency in 24-well tissue culture plates. Once confluent, VK2 cells were treated with AKB-4924 $(8 \mu \mathrm{g} / \mathrm{mL})$ or vehicle control for $5 \mathrm{~h}$. Cells were infected with GBS COH 1 at $\mathrm{MOI}=1$ or 0.1 (assuming $1 \times 10^{6}$ VK2 cells per well). GBS was brought into contact with the VK2 cells by centrifuging for $1 \mathrm{~min}$ at $300 \mathrm{~g}$. After $30 \mathrm{~min}$, supernatant was removed and cells washed $6 \times$ with sterile PBS. Cell layers were incubated for 5 min with $100 \mu \mathrm{L} 0.25 \%$ trypsin/2.21 mM EDTA after which $400 \mu \mathrm{L}$ of $0.025 \%$ Triton-X in PBS was added. Wells were mixed $30 \times$ to ensure detachment, and GBS recovery was determined by plating on THA plates using serial dilution and counting CFUs. Data was expressed as a percentage of adherent CFUs compared to original inoculum. 
ELISAs

Adapted from previous methods [37], VK2 cells were infected with GBS COH1 as described above with several modifications; GBS were added at MOI $=10$, and cells were incubated for $3 \mathrm{~h}$. Where indicated, VK2 cells were pretreated with $8 \mu \mathrm{g} / \mathrm{mL}$ AKB4924 for $5 \mathrm{~h}$ prior to infection with GBS. Supernatant from VK2 cells was probed for presence of human IL-1 $\beta$ (R\&D Systems, Cat\# DY201) and IL-8 (RひD Systems, Cat\# DY208) following manufacturer protocols.

\section{Animals}

The UCSD Institutional Animal Care and Use Committee (Protocol \#S00227M) approved all animal protocols and procedures. Wild-type (WT) C57BL/6 mice aged 8-10 weeks were purchased from Jackson Labs. Epithelial tissue-specific and myeloidspecific knockouts of HIF-1 a was accomplished by back-crossing C57Bl/6 HIF-1 $\alpha^{\mathrm{fl} / \mathrm{fl}}$ mice (Jackson Laboratory, Stock No. 007561) with K14cre+ (epithelial cell specific, Jackson Laboratory, Stock No. 004782) or LysMcre+ transgenic mice (myeloid lineage, Jackson Laboratory, Stock No. 004781). Cre-negative HIF-1 $\mathrm{a}^{\mathrm{fl} / \mathrm{fl}}$ littermates were used as controls for all experiments [25, 32, 39]. To ensure statistical power in compliance with ethical guidelines, at least 5 mice per group were used. Treatment groups were assigned randomly and housed in separate cages. Mice were allowed to eat and drink ad libitum.

\section{Bone Marrow-Derived Macrophage Collection and}

\section{Differentiation}

As described previously [40], fresh bone marrow collected from murine femur and tibia was plated on $10 \mathrm{~cm}$ dishes. Dulbecco's Modified Eagle Medium (Gibco) containing 10\% NIH 3T3 cell conditioned media, 20\% FBS, and 1\% nonessential amino acids was added to the bone marrow cells, which were then left to differentiate for at least 6 days. Fresh media was added at day 3 and day 6. At day 10, the bone-marrow derived macrophages (BMD$\mathrm{Ms}$ ) were reseeded in 96-well plates to be used for in vitro assays.

\section{Thioglycolate-Induced Neutrophil-Enriched Immune Cell \\ Isolation}

To obtain a neutrophil enriched population, neutrophil migration was stimulated by injection of $1 \mathrm{~mL}$ of $3 \%$ thioglycolate intraperitoneally as described previously [38]. Briefly, HIF- $1 a^{\mathrm{fl} / \mathrm{fl}}$ LysMcre+ and HIF- $1 \alpha^{\mathrm{fl} / \mathrm{fl}}$ mice were intraperitoneally injected with $3 \%$ thioglycolate, and $24 \mathrm{~h}$ after injection, peritoneal lavage was performed using PBS with $5 \mathrm{~mm}$ ethylenediaminetetraacetic acid (EDTA). Polymorphonuclear cells (PMN) composed $80-85 \%$ of the total cell population, as determined by Giemsa staining (online suppl. Fig. 2d). Cells were resuspended in RPMI-1640 + 2\% FBS.

\section{In vitro Phagocytosis and Intracellular Killing Assays}

Thioglycolate-elicited cells were seeded at $2 \times 10^{5}$ cells per well and BMDMs were seeded at $5 \times 10^{4}$ cells per well. Cells were infected with GBS COH1 at MOI $=10$. For opsonization experiments, GBS was incubated in $20 \%$ pooled human serum for $10 \mathrm{~min}$ prior to infection. GBS was brought into contact with the cells by centrifuging for $5 \mathrm{~min}$ at $500 \mathrm{~g}$ and then incubated at $37^{\circ} \mathrm{C}$ for 10 min. To kill extracellular bacteria, the media was then replaced with RPMI-1640 + 2\% FBS + penicillin $(0.5 \mu \mathrm{g} / \mathrm{mL})+$ gentamicin $(2 \mu \mathrm{g} / \mathrm{mL})$ and incubated for $25 \mathrm{~min}$ (see online suppl. Fig. $2 \mathrm{~b}$ ). Cells were then washed twice with PBS and media was replaced with fresh RPMI-1640 + 2\% FBS without antibiotics. For phagocytosis assays, cells were lysed immediately with $1 \%$ Triton X-100 and lysate was serial diluted and plated for CFUs. For in vitro intracellular killing assays, cells were incubated at $37^{\circ} \mathrm{C}+5 \% \mathrm{CO}_{2}$ for 60,90 , or $120 \mathrm{~min}$ prior to lysis with Triton X-100, serial dilution, and plating for CFUs. CFU values normalized to T0. For the AKB4924 intracellular killing assays, the wells were pretreated for $4 \mathrm{~h}$ with $12 \mu \mathrm{g} / \mathrm{mL}$ AKB- 4924 or vehicle before infection. Cell viability was determined at 0,60 , and $120 \mathrm{~min}$ by aspirating the culture media and adding $50 \mu \mathrm{L}$ of staining media with Hoechst at $1 \mu \mathrm{g} / \mathrm{mL}$ and propidium iodide at $0.5 \mu \mathrm{g} / \mathrm{mL}$. Cells were incubated with staining media for $10 \mathrm{~min}$. The staining media was then aspirated and cells washed twice with PBS before mounting and visualization using a Zeiss Axio Scope.A1.

\section{GBS Vaginal Colonization}

Colonization experiments were performed as previously described [41]. In short, C57BL/6 WT, HIF-1a $\alpha^{\mathrm{fl} / \mathrm{fl}} \mathrm{K} 14 \mathrm{cre}+$ or littermate HIF- $1 \alpha^{\mathrm{fl} / \mathrm{fl}} \mathrm{K} 14 \mathrm{cre}-\left(\mathrm{HIF}-1 \alpha^{\mathrm{fl} / \mathrm{fl}}\right)$ female mice were treated intraperitoneally (i.p.) with $0.5 \mathrm{mg} \beta$-estradiol in $100 \mu \mathrm{L}$ sesame oil $(5 \mathrm{mg} / \mathrm{mL})$ to synchronize estrus. After $24 \mathrm{~h}$, mice were vaginally inoculated with $1 \times 10^{7} \log$-phase GBS COH1 or A909 as indicated in Figure Legends. Colonization was monitored daily by collecting vaginal swabs (Puritan, Cat. \# 25-801 A 50). Bacterial load was determined by serial dilution plating on CHROMagar ${ }^{\mathrm{TM}}$ StrepB base (DRG International Inc.). To investigate the effect of HIF-1a stabilization on GBS colonization, mice were either: (1) pretreated vaginally with $10 \mu \mathrm{L}$ (40 $\mu$ g AKB-4924/dose) $24 \mathrm{~h}$ prior to GBS inoculation and daily thereafter for the duration of the experiment, or (2) i.p. injected with $200 \mu \mathrm{L}(200 \mu \mathrm{g} /$ dose $)$ of AKB-4924 $24 \mathrm{~h}$ prior to and $24 \mathrm{~h}$ after GBS inoculation. Control mice were treated with vehicle doses. Because no significant differences were observed between dosing strategies, results were combined in Figure $2 \mathrm{~d}$.

\section{In vivo Mouse Model of GBS Infection}

The UCSD Institutional Animal Care and Use Committee (Protocol \#S00227M) approved the anticipated mortality and study design. For in vivo survival studies, C57BL/6 WT, HIF$1 a^{\mathrm{fl} / \mathrm{fl}}$ LysMcre+ or littermate HIF- $1 a^{\mathrm{fl} / f l}$ LysMcre- $\left(\mathrm{HIF}-1 \alpha^{\mathrm{fl} / \mathrm{fl}}\right.$ ) male and female mice were i.p. injected with $100 \mu \mathrm{L}$ of PBS containing $5 \times 10^{7}$ to $2 \times 10^{8}$ GBS COH1 CFUs (specified in each figure). Where indicated, mice received an i.p. injection of $200 \mu \mathrm{L}$ (200 $\mu \mathrm{g}$ AKB-4924/dose) 1 day prior to infection, the day of infection, and daily thereafter for 3 days. Mice were monitored 3 times daily for the duration of 7 days for mortality. Analgesics were not administered during systemic infection due to potential effects on the study outcome. The mice were humanely euthanized with $\mathrm{CO}_{2}$ asphyxiation if they survived to study end point (day 7, total $n$ from Fig. $3=6$, and Fig. $4=25$ ).

\section{Neutrophil Killing and ROS Assays}

Neutrophil killing and ROS experiments were conducted as previously described [38]. Briefly, venous blood specimens were treated with heparin for anticoagulation. Neutrophils were isolated using PolymorphPrep (Axis-Shield), subsequently infected with GBS COH1 at an MOI of 1 for $30 \mathrm{~min}$, plated on THA, and GBS survival was calculated as a percentage of the inoculum. For the ROS assays, isolated neutrophils were treated with either vehicle, vehicle + PMA, AKB-4924, or AKB-4924 + PMA, in the pres- 


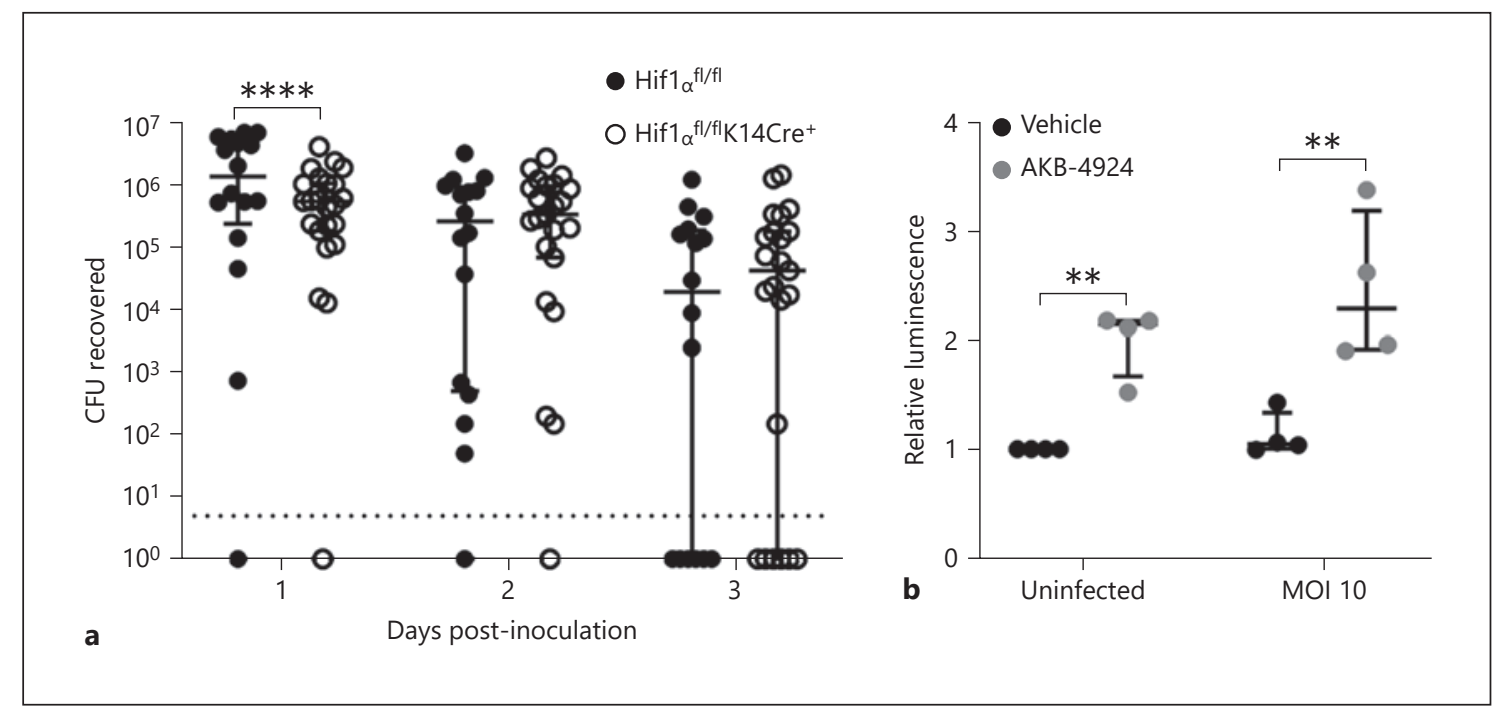

Fig. 1. Role of endogenous HIF-1a in GBS colonization of the vaginal tract epithelium. a HIF- $1 \alpha^{\mathrm{fl} / \mathrm{fl}}$ and HIF- $1 \alpha^{\mathrm{fl} / \mathrm{fl}} \mathrm{K} 14 \mathrm{Cre}+$ female mice were vaginally administered $2 \times 10^{7}$ CFUs of GBS COH1. Mice were vaginally swabbed daily, and the levels of GBS CFU recovered from swabs are shown. b Normalized bioluminescence of VK2 HRE reporter cells infected with GBS COH1 MOI of 20 for $2 \mathrm{~h}$. AKB-4924 treatment $(12 \mu \mathrm{g} / \mathrm{mL})$ was included as a positive control. Symbols represent biological replicates (a, $n=16-23$ /

ence or absence of GBS COH1 at an MOI of 10. Total ROS was measured at $30 \mathrm{~min}$ intervals for a total of $120 \mathrm{~min}$ as previously described [36]. AKB-4924 pretreatment was at a concentration of $8 \mu \mathrm{g} / \mathrm{mL}$ for $30 \mathrm{~min}$ and PMA treatment was added at a concentration of $25 \mathrm{nM}$.

\section{Neutrophil Extracellular Trap Assays}

Human neutrophils isolated as described above, were treated with AKB-4924 (8 $\mu \mathrm{g} / \mathrm{mL})$ for $30 \mathrm{~min}$, or vehicle control, and subsequently challenged with GBS COH1 at an MOI of 10 for $4 \mathrm{~h}$. A subset of uninfected cells was instead treated with PMA (25 nM) to serve as a positive control for NET formation. Neutrophil extracellular trap (NET) formation was quantified as previously described [36]. Briefly, micrococcal nuclease $(500 \mathrm{mU} / \mathrm{mL})$ was added for 10 min to digest extracellular DNA. The samples were centrifuged at $200 \mathrm{~g}$ for $8 \mathrm{~min}$ and then sample supernatant was transferred to a new 96-well plate. DNA was quantified using a Quant-iT PicoGreen ${ }^{\circledR}$ dsDNA Assay Kit from Life Technologies (Carlsbad, CA, USA).

\section{Statistical Analysis}

In vitro and ex vivo experiments were repeated at least 3 times independently with at least 3 technical replicates. Mean values from independent experiments were used to represent biological replicates for statistical analyses. In vivo experiments were conducted at least twice independently which each mouse serving as a biological replicate. Experimental data was combined prior to statistical analyses. All data sets were subjected to D'Agostino \& Pearson normality test to determine whether values displayed Gaussian group) or the means of 4 independent experimental replicates (b, performed in technical triplicate) with lines indicating medians and interquartile ranges. Dotted line in (a) indicates limit of detection. Data were analyzed by two-way ANOVA with Sidak's multiple comparisons posttest. ${ }^{* * * *} p<0.0001{ }^{* *} p<0.01$. HRE, hypoxia response element; GBS, group B Streptococcus; HIF-1a, hypoxia-inducible factor 1 alpha; CFU, colony-forming unit. distribution before selecting the appropriate parametric or nonparametric analyses. In instances where experimental numbers $(n)$ were too small to determine normality (Fig. 1b, 2a-c, 3a-f and 4 online suppl. Fig. 1b, 2a-e, 3a-c), data were assumed nonparametric. Two-way ANOVA with Sidak's multiple comparisons posttest was used to analyze GBS vaginal colonization, VK2-HRE and RAW-HRE reporter cells, VK2 cytokine production, cell viability, and GBS intracellular survival in BMDMs and thioglycolate-elicited cells. Mann-Whitney test was used to analyze qPCR and neutrophil populations. Wilcoxon matched-pairs signed rank test was used to analyze opsonized and nonopsonized GBS phagocytosis by BMDMs and GBS adherence to VK2 cells. Log-rank (Mantel-Cox) test was used to analyze in vivo survival curves. Statistical analyses were performed using GraphPad Prism, version 9.0.1 (GraphPad Software Inc., La Jolla, CA, USA). $p$ values $<0.05$ were considered statistically significant.

\section{Results}

Endogenous Vaginal Epithelial HIF-1 $\alpha$ Levels Are Not Enhanced by GBS and Epithelial Cell-Specific HIF-1 $\alpha$ Deficiency Does Not Alter GBS Vaginal Colonization in vivo

Because HIF-1 $\alpha$ is an important host immune regulator in response to several bacterial pathogens at the epi- 


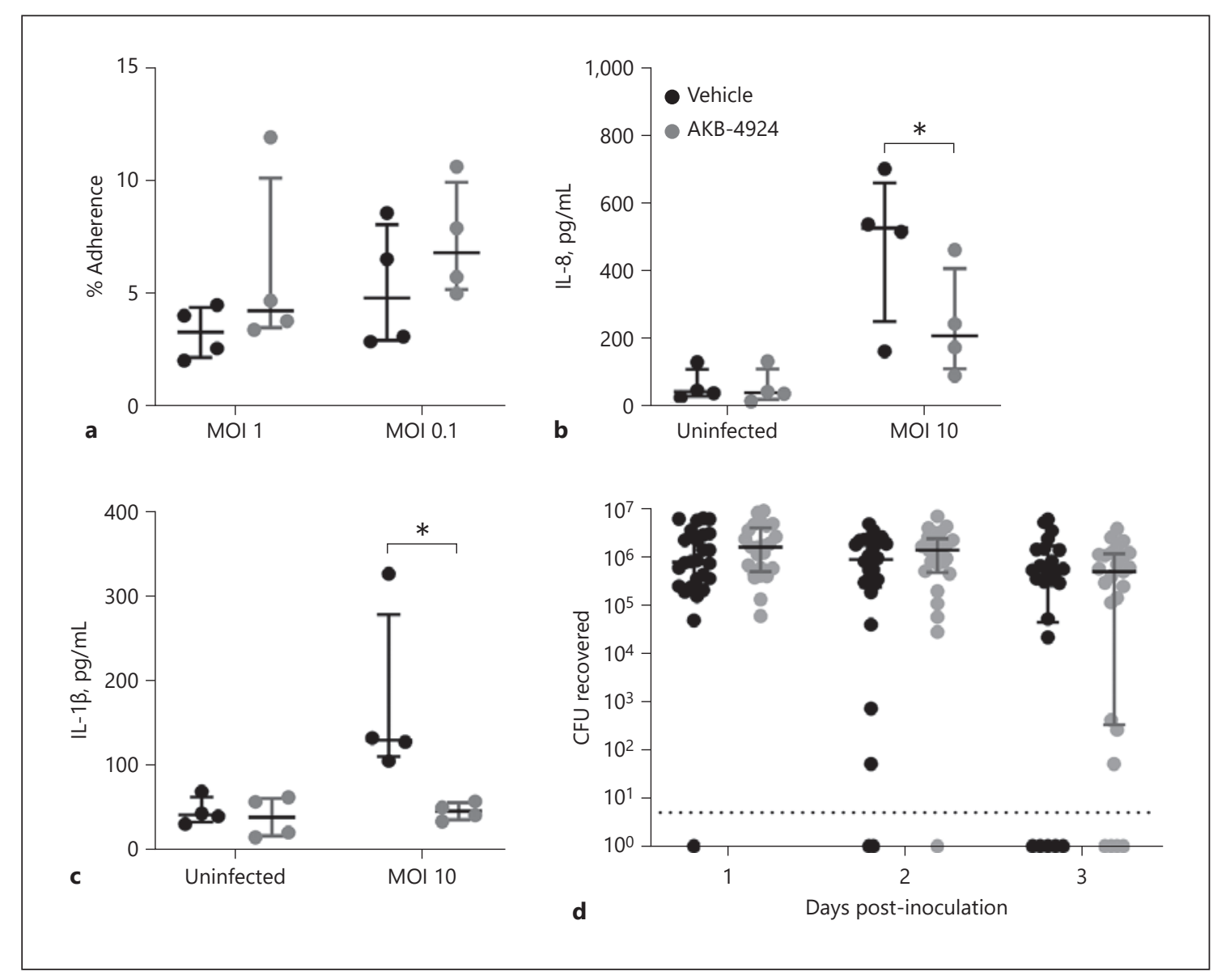

Fig. 2. Impact of HIF-1a stabilization on vaginal epithelial GBS colonization and cytokine production. a Percent adherence of GBS $\mathrm{COH} 1$ to VK2 cells after 30 min of infection, $\mathrm{MOI}=0.1$ or 1 . VK2 cells were pretreated for $5 \mathrm{~h}$ with $12 \mu \mathrm{g} / \mathrm{mL}$ AKB- 4924 or vehicle treated as a control. Production of IL-8 (b) or IL-1 $\beta$ (c) was measured from VK2 supernatant after $3 \mathrm{~h}$ of infection with GBS COH1, $\mathrm{MOI}=10$. VK2 cells were pretreated for $5 \mathrm{~h}$ with $12 \mu \mathrm{g} / \mathrm{mL}$ AKB4924 or vehicle treated as a control. d WT C57Bl/6 female mice were vaginally administered $2 \times 10^{7} \mathrm{CFUs}$ of GBS COH1. Mice were vaginally swabbed daily, and the levels of GBS CFU recovered from swabs are shown. Mice were treated vaginally or i.p. with AKB-4924, or vehicle as a control, as described in Methods. Symbols represent means of 4 independent experimental replicates (ac, performed in technical triplicate) or biological replicates (d, $n=$ 25-26/group) with lines indicating medians and interquartile ranges. Dotted line in $(\mathbf{d})$ indicates limit of detection. Data were analyzed by two-way ANOVA with Sidak's multiple comparisons posttest (b-d) or Wilcoxon matched-pairs signed rank test (a). ${ }^{*} p<0.05$. GBS, group B Streptococcus; HIF-1a, hypoxia-inducible factor 1 alpha; CFU, colony-forming unit; WT, wild type. thelial surface, we assessed the role of HIF-1a expression in the vaginal epithelium during GBS colonization. Using a mouse line harboring keratinocyte-specific inactivation of HIF- $1 \alpha$ as described previously [33], HIF- $1 \alpha$-sufficient $\left(\mathrm{HIF}-1 \alpha^{\mathrm{fl} / \mathrm{fl}}\right.$ ), and keratinocyte HIF-1 $\alpha$-deficient (HIF$\left.1 a^{\mathrm{f} / / \mathrm{fl}} \mathrm{K} 14 \mathrm{Cre}+\right)$ mice were inoculated with $2 \times 10^{7} \mathrm{GBS}$ CFUs of strain $\mathrm{COH} 1$ directly into the vaginal lumen. Vaginal swabs were collected daily to quantify GBS burden. Although the absence of keratinocyte HIF-1a expression (Cre+ mice) led to a slight, but significantly decreased GBS burden on day 1 postinoculation compared to Cre- mice, this effect did not persist at later time points (Fig. 1a). Additionally, using a different GBS clinical isolate, A909, we observed the opposite phenotype with HIF-1 $\alpha$-deficient mice displaying higher GBS burdens than HIF-1 $\alpha$-sufficient mice on day 1 (online suppl. Fig. 1a). Similar to Fig. 1a, no significant differences were observed on subsequent days. To determine if GBS exposure stimulates HIF-1a expression in vaginal epithelial cells, we constructed a HIF-1 $a$ reporter system in human vaginal epithelial cell line VK2 (VK2-HRE reporter cells) using the lentiviral vector mCMV-HRE-luciferase as de- 


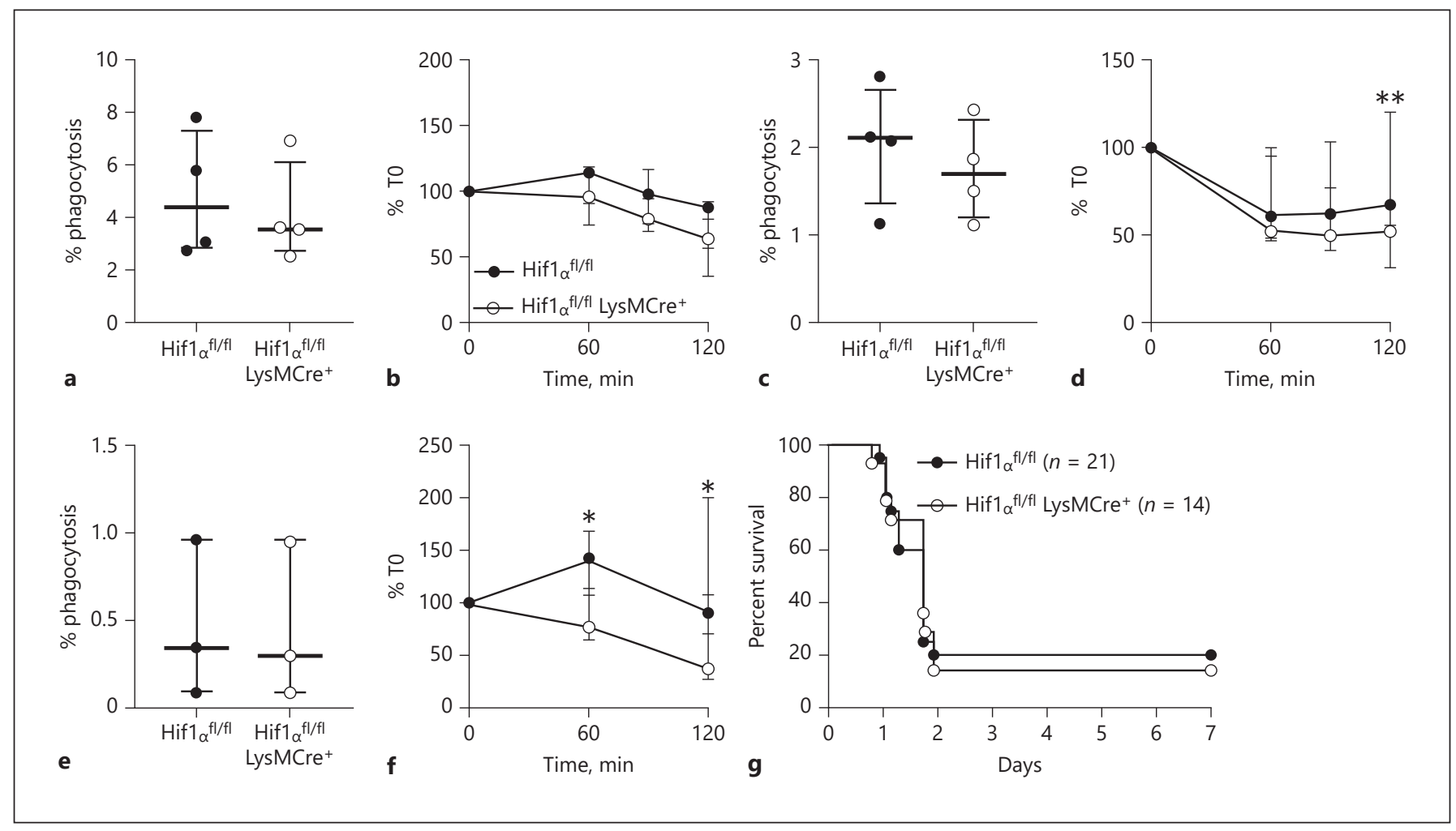

Fig. 3. Role of endogenous HIF-1 $\alpha$ in GBS phagocytosis, intracellular survival, and host morbidity in a murine model of GBS sepsis. BMDMs or thioglycolate-elicited cells were isolated from HIF$1 \mathrm{a}^{\mathrm{fl} / \mathrm{fl}}$ and HIF-1 $\mathrm{a}^{\mathrm{f} / \mathrm{fl}} \mathrm{K} 14 \mathrm{Cre}+$ and infected with GBS COH1 at MOI $=10$. GBS uptake and intracellular survival were assessed as described in Methods. Percent nonopsonized GBS uptake (a) and intracellular GBS survival (b) in BMDMs. Percent opsonized GBS uptake (c) and intracellular GBS survival (d) in BMDMs. Percent opsonized GBS uptake (e) and nonopsonized intracellular GBS survival (f) in thioglycolate-elicited cells. g HIF- $1 a^{\mathrm{fl} / f l}$ and HIF$1 a^{\mathrm{fl} / \mathrm{fl}}$ LysMCre+ mice were infected intraperitoneally with

scribed previously [36]. Briefly, VK2-HRE reporter cells were infected with GBS COH1 at MOI $=20$ for $2 \mathrm{~h}$ and cell luminescence were quantified. As a control, VK2HRE reporter cells were treated with $12 \mu \mathrm{g} / \mathrm{mL}$ of AKB4924, a pharmacologic stabilizer of HIF-1a [34]. GBS infection of VK2-HRE reporter cells was not sufficient to induce HIF-1 1 a expression (Fig. 1b). HIF-1a levels were increased in both uninfected and GBS-infected cells only when the cells were co-treated with the HIF-1 $\alpha$ stabilizer AKB-4924 (Fig. 1b), demonstrating the sensitivity of the assay in detecting HIF-1 $\alpha$. Furthermore, a GBS mutant, $\Delta c y l E$, which is deficient in $\beta$-hemolysin production and shows attenuated toxicity and cytokine responses in VK2 cells [19], was also insufficient to induce luciferase activity (online suppl. Fig. 1b) suggesting GBS hemolysin-me-
$5 \times 10^{7} \mathrm{CFU}$ GBS and survival monitored over 7 days. Symbols and error bars represent means \pm standard error $(\mathbf{a}, \mathbf{c}, \mathbf{e})$ or medians \pm interquartile ranges $(\mathbf{b}, \mathbf{d}, \mathbf{f})$ of 3 or 4 independent experimental replicates. In G, symbols represent death time points on a survival curve ( $n=14-21 /$ group) with lines indicating percentage survival between time points. Data were analyzed by Wilcoxonmatched pairs signed rank test (a, $\mathbf{c}, \mathbf{e})$, two-way ANOVA with Sidak's multiple comparisons posttest (b, d, f), or log-rank (Mantel-Cox) test $(\mathbf{g}) .{ }^{* *} p<0.01 ;{ }^{*} p<0.05$. BMDM, bone marrow-derived macrophage; GBS, group B Streptococcus; HIF-1a, hypoxiainducible factor 1 alpha; CFU, colony-forming unit. diated toxicity does not actively inhibit HIF-1a expression in this cell line.

\section{Enhancing HIF-1 $\alpha$ Stabilization Lowers Vaginal} Epithelial Cytokine Production in Response to GBS, but Does Not Alter GBS Interactions with the Vaginal Tract in vitro or in vivo

Previous studies have reported altered bacterial cell interactions and downstream immune effects during pharmacologic enhancement of HIF-1 $\alpha[32,34]$. We interrogated the role of HIF-1 $\alpha$ in GBS adhesion to human vaginal epithelial cells and the subsequent cytokine responses. Vaginal epithelial VK2 cells were pretreated with the HIF-1 a stabilizer AKB-4924, or vehicle, for $5 \mathrm{~h}$, subsequently infected with GBS at MOI $=0.1$ or 1 and 


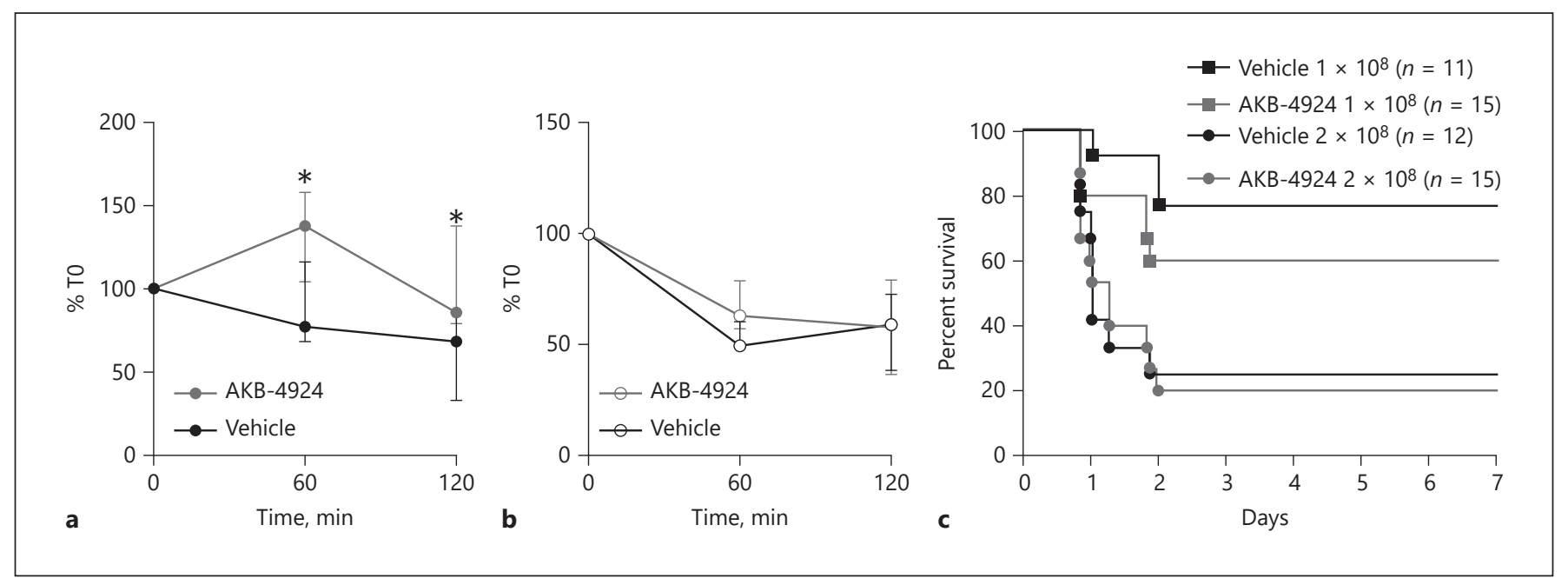

Fig. 4. Impact of HIF-1a stabilization on GBS intracellular survival and host morbidity in a murine model of GBS sepsis. BMDMs were isolated from HIF- $1 \alpha^{\mathrm{fl} / \mathrm{fl}}(\mathbf{a})$ and HIF- $1 \alpha^{\mathrm{fl} / \mathrm{fl}} \operatorname{LysMCre}+(\mathbf{b})$, treated with AKB-4924 or a vehicle control, and infected with GBS $\mathrm{COH} 1$ at $\mathrm{MOI}=10$. Intracellular GBS survival was assessed as described in Methods. c WT C57Bl/6 mice were pretreated with AKB-4924, or a vehicle control, and infected intraperitoneally with $1 \times 10^{8}$ or $2 \times 10^{8} \mathrm{CFU}$ GBS COH1 and survival monitored over 7 days. Symbols represent the median of 4 or 5 independent experi-

evaluated for GBS adherence after 30 min of incubation. Stabilization of HIF-1a with AKB-4924 did not alter GBS adherence to vaginal epithelial cells at $\mathrm{MOI}=0.1$ or MOI $=1$ (Fig. 2a). To evaluate the impact of HIF-1a stabilization on cytokine production, VK2 cells, pretreated with AKB-4924 as above, were infected with GBS COH1 at $\mathrm{MOI}=10$, or uninfected as a control, and evaluated for IL- 8 and IL- $1 \beta$ production in the cell supernatant after $3 \mathrm{~h}$. GBS infection increased IL-8 levels in the supernatant over uninfected controls as expected (Fig. 2b), yet AKB4924 treatment did not further increase cytokine production. Rather, HIF-1 $\alpha$ stabilization in GBS infected cells led to significantly decreased IL- 8 compared to vehicle-treated GBS infected cells (Fig. 2b). Similarly, GBS infection increased IL- $1 \beta$ production over uninfected controls (Fig. 2c) and, likewise, AKB-4924 treatment of GBS infected cells led to significantly decreased IL-1 $\beta$ compared to vehicle-treated GBS infected cells (Fig. 2c). AKB-4924 treatment alone did not affect the levels of IL- 8 and IL-1 $\beta$ produced by uninfected VK2 cells (Fig. 2b, c). To assess whether pharmacologic stabilization of HIF-1 $\alpha$ would impact GBS vaginal colonization in vivo, WT C57Bl/6 mice were treated with 5 doses of AKB-4924 either IP or intravaginally, as detailed in the Methods section, prior to and during colonization with $10^{7}$ CFUs of GBS COH1. mental replicates (a, b, performed in technical triplicate), with lines indicating medians and interquartile ranges. In (c) symbols represent death time points on a survival curve ( $n=11$-15/group) with lines indicating percentage survival between time points. Data were analyzed by two-way ANOVA with Sidak's multiple comparisons posttest $(\mathbf{a}, \mathbf{b})$, or log-rank (Mantel-Cox) test $(\mathbf{c}) .{ }^{*} p<$ 0.05 . BMDM, bone marrow-derived macrophage; GBS, group B Streptococcus; HIF-1a, hypoxia-inducible factor 1 alpha; CFU, colony-forming unit; WT, wild type.

AKB-4924 did not significantly alter GBS vaginal burdens compared to vehicle controls at any time point over the first 3 days of colonization (Fig. 2d).

\section{Myeloid Cell-Specific HIF-1 $\alpha$ Deficiency Decreases}

GBS Intracellular Survival ex vivo, but Does Not Alter

Host Outcomes in vivo

Because HIF-1a is a critical regulator of myeloid cell inflammatory and antibacterial responses towards multiple pathogens $[25,42]$, we assessed the impact of myeloid cell-specific HIF-1 $\alpha$ deficiency using a mouse line harboring Cre expression driven be the lysozyme $\mathrm{M}$ (LysMCre) as previously described [25, 42]. BMDMs from HIF-1 $1 \alpha$-sufficient (HIF-1 $\alpha^{\mathrm{fl} / \mathrm{fl}}$ ) and myeloid HIF$1 \alpha$-deficient (HIF-1 $\alpha^{\mathrm{f} / \mathrm{fl}}$ LysMCre+) were isolated and differentiated ex vivo. Efficiency of HIF-1a deletion in HIF- $1 a^{\mathrm{f} / / \mathrm{fl}}$ LysMCre+ BMDMs was confirmed by qPCR (online suppl. Fig. 2a). We performed an in vitro phagocytosis assay by infecting BMDMs with GBS strain $\mathrm{COH} 1$ $\left(5 \times 10^{5} \mathrm{CFUs}\right)$ followed by antibiotic treatment to eliminate extracellular GBS. No differences in bacterial uptake were observed between HIF-1 $\alpha$-sufficient (HIF- $1 \alpha^{\mathrm{fl} / \mathrm{fl}}$ ) and HIF-1 $\alpha$-deficient (HIF- $1 \alpha^{\mathrm{fl} / \mathrm{fl}}$ LysMCre+) BMDMs (Fig. 3a). To determine the impact of HIF-1a deficiency on macrophage control of intracellular GBS, BMDMs 
were infected with $\mathrm{COH} 1\left(5 \times 10^{5} \mathrm{CFUs}\right)$, treated with antibiotics to eliminate extracellular GBS, and intracellular GBS quantified over the span of $2 \mathrm{~h}$. Elimination of extracellular GBS was confirmed under the assay conditions (online suppl. Fig. 2b). No differences in GBS intracellular survival were observed at any time point between HIF-1 $\alpha$-sufficient and HIF-1 $\alpha$-deficient BMDMs (Fig. 3b).

To enhance GBS uptake and thus increase potential phenotypes due to HIF-1 $\alpha$ deficiency, we repeated these assays under opsonizing conditions. Although total numbers of recovered intracellular GBS were higher in opsonizing compared to nonopsonizing conditions (Fig. 3a), no differences in bacterial uptake were observed between HIF-1 $\alpha$-sufficient and HIF-1 $\alpha$-deficient BMDMs (Fig. 3c). Additionally, we performed intracellular GBS survival assays as above, but under opsonizing conditions. Overall, we observed enhanced BMDM control of intracellular opsonized GBS compared to nonopsonized GBS (Fig. 3b), but differences between HIF- $1 \alpha^{\mathrm{fl} / \mathrm{fl}}$ and HIF- $1 \alpha^{\mathrm{fl} / \mathrm{fl}}$ LysMCre+ were modest, and only achieved significance at the $120 \mathrm{~min}$ time point (Fig. 3d). Counter to our hypothesis, HIF-1 $\alpha$-deficient (HIF-1 $\alpha^{\mathrm{fl} / \mathrm{fl}}$ LysMCre+) BMDMs showed greater reduction of intracellular GBS compared to HIF-1a-sufficient (HIF-1a $\alpha^{\mathrm{f} / \mathrm{fl}}$ ) BMDMs at this time point. Cell viability assessed by a Hoechst and propidium iodide co-stain showed no differences in BMDM viability between genotypes across assay conditions (online suppl. Fig. 2c). To test whether this phenotype extended to other myeloid cell populations, we stimulated myeloid migration into the murine peritoneal cavity using a single intraperitoneal injection of thioglycolate [38]. After a 24-h stimulation, peritoneal lavage was performed and recovered cell populations were distinguished morphologically using Giemsa staining. Total leukocyte populations were similar between HIF- $1 a^{\mathrm{fl} / f \mathrm{l}}$ and HIF- $1 \alpha^{\mathrm{fl} / \mathrm{fl}}$ LysMCre+ mice and comprised of $>75 \%$ polymorphonuclear cells (online suppl. Fig. 2d). Thioglycolate-elicited cells were infected with $5 \times 10^{6} \mathrm{CFUs}$ nonopsonized GBS (MOI = 10) and GBS phagocytosis and intracellular GBS survival were assessed as above in opsonizing and nonopsonizing conditions, respectively. Specifically, GBS phagocytosis was assessed solely under opsonizing conditions and not in nonopsonizing conditions, whereas intracellular GBS survival was assessed solely in nonopsonizing conditions. Similar to BMDM results, no significant differences in opsonized GBS uptake were observed between thioglycolate-elicited HIF$1 \alpha^{\mathrm{f} / / \mathrm{fl}}$ and HIF- $1 \alpha^{\mathrm{f} / / \mathrm{fl}}$ LysMCre+ cells (Fig. 3e). Notably, thioglycolate-elicited cell control of nonopsonized intra-

HIF-1a Is Dispensable for Defense against GBS cellular GBS was enhanced in HIF- $1 \alpha^{\mathrm{fl} / \mathrm{fl}}$ LysMCre+ compared to HIF-1 $\alpha^{\mathrm{fl} / \mathrm{fl}}$ cells (Fig. 3f) as seen with BMDM assays using opsonized GBS (Fig. 3d). To determine whether GBS infection stimulated HIF-1a stabilization in macrophages, we generated a HIF-1 $\alpha$ reporter system in the murine macrophage cell line RAW 264.7 (RAWHRE) in the same manner that we construct the VK2HRE reporter cells. RAW-HRE reporter cells were infected with GBS COH1 at MOI $=20$ for $2 \mathrm{~h}$ and cell luminescence was quantified. As a control, RAW-HRE reporter cells were treated with $12 \mu \mathrm{g} / \mathrm{mL}$ of AKB-4924. GBS infection of RAW-HRE reporter cells was not sufficient to induce HIF-1a expression (online suppl. Fig. 2e). HIF-1a levels were increased in both uninfected and GBS-infected cells only when the cells were co-treated with the HIF1a stabilizer AKB-4924 (online suppl. Fig. 2e) demonstrating the sensitivity of the assay in detecting HIF-1a. Furthermore, a GBS mutant, $\Delta c y l E$, was also insufficient to induce luciferase activity (online suppl. Fig. 2e). To interrogate whether HIF-1a deficiency in myeloid cells alters the course of infection in vivo, HIF- $1 \alpha^{\mathrm{fl} / f \mathrm{l}}$ and HIF$1 a^{\mathrm{f} / / \mathrm{fl}}$ LysMCre+ mice were infected intraperitoneally with $5 \times 10^{7}$ CFUs GBS and survival monitored over 7 days. No differences in animal survival were observed between genotypes (Fig. 3g).

Enhancing HIF-1 $\alpha$ Stabilization Reduces Macrophage Control of GBS in vitro, but Does Not Impact Human

Neutrophil Control of GBS nor Alter Host Outcome

during GBS Systemic Infection in vivo

Because deficiency of HIF-1a in myeloid lineage cells only minimally impacted GBS phagocytosis and intracellular survival in vitro, nor did it alter host outcomes in a sepsis model, we next investigated whether systemic pharmacologic boosting of HIF-1a would improve host control of GBS. As done in Fig. 3, BMDMs isolated from HIF- $1 \alpha^{\mathrm{f} / / \mathrm{fl}}$ and HIF- $1 \alpha^{\mathrm{fl} / f \mathrm{l}}$ LysMCre+ mice were pretreated with AKB- 4924 for $4 \mathrm{~h}$ prior to GBS intracellular killing assays as described above. Pretreatment with AKB4924 significantly reduced the ability of HIF- $1 \alpha$-sufficient (HIF-1 $\alpha^{\mathrm{fl} / \mathrm{fl}}$ ) BMDMs to control opsonized GBS (Fig. 4a), but this effect was absent in HIF-1 $\alpha$-deficient (HIF-1 $\alpha^{\mathrm{fl} / \mathrm{fl}}$ LysMCre+) BMDMs (Fig. 4b). This observation suggests enhancement of HIF-1 $\alpha$ may modulate innate immune responses to GBS. To assess whether this finding translated to human cells, we assessed whether AKB-4924 treatment of human peripheral neutrophils altered neutrophil control of GBS. There were no differences in GBS survival or formation of neutrophil extracellular traps between AKB-4924 treatment and vehicle conditions, al- 
though AKB-4924-treated cells had decreased ROS release compared to vehicle treated cells across vehicle, GBS-infected, and PMA-stimulated conditions (online suppl. Fig. 3a-c). To interrogate how boosting of HIF-1a impacts host susceptibility to GBS systemic infection, C57Bl/6J mice were treated IP with AKB-4924 prior to infection with GBS, or treated with vehicle as a control. We tested 2 different doses of GBS, $1 \times 10^{8}$ CFUs and $2 \times$ $10^{8}$ CFUs, which resulted in $\sim 80 \%$ survival and $\sim 20 \%$ survival in vehicle-treated mice, respectively, over 7 days. No differences in animal survival were observed between AKB-4924 and vehicle-treated mice at either dosage (Fig. 4c).

\section{Discussion}

The role of HIF-1 $\alpha$ in orchestrating immune responses to bacterial pathogens has recently been established in a variety of conditions ranging from urinary tract infection, to polymicrobial sepsis, to necrotizing fasciitis. In this study, we investigate the role of HIF-1 $\alpha$ in host defense against the important neonatal pathogen GBS using genetic tools, pharmacologic agents, and murine models of systemic infection and colonization. Our findings suggest that HIF-1 $\alpha$ is not a key mediator of immune responses to GBS and do not provide encouragement for pursuit of therapeutic applications modulating HIF-1a to limit GBS colonization or disease.

Unlike similar studies with various Gram-negative and Gram-positive bacterial pathogens [25, 31-34, 43], we observed no effect of HIF-1 a modulation on GBS vaginal persistence nor disease severity in our mouse models of GBS vaginal colonization and systemic infection, respectively. Our murine models have several limitations, however. Because global deletion of HIF-1a is embryonic lethal, loss of HIF-1 $\alpha$ in our mouse lines is cell lineage specific and dependent on the efficiency of Cre recombinase within the target cell type. Thus, it is possible that compensatory activity of HIF-1 $\alpha$ by other cell types in our murine models may mask any phenotypes linked to keratinocyte or myeloid HIF-1a deficiency. Additionally, we did not extensively optimize the dosage or time of pharmacologic enhancement of HIF-1 $\alpha$ in our model systems, but rather, extended timing and dosage regimens from previous studies showing potent AKB-4924 effects [32, 44]. Even with these limitations, we conclude that the lack of robust phenotypes in both our genetic and pharmacological studies with GBS, which have proved insightful tools for other bacterial pathogens, do not scientifically justify additional animal experimentation at this point in time.

There is a paucity of data on the role of HIF-1 $\alpha$ in the female urogenital tract, although production of HIF-1a has been detected in vaginal stromal cells [45] and in placental cytotrophoblasts [46]. Indeed, treatment with AKB-4924-induced robust stabilization in our vaginal epithelial cell HRE-reporter cell line indicating HIF-1 $\alpha$ is produced by this cell type. Interestingly, vaginal epithelial (VK2) infection with GBS did not itself stimulate HIF$1 a$ during normoxic conditions, nor did we detect evidence for GBS suppression of HIF-1 1 due to toxicity; an attenuated GBS mutant $(\Delta c y l E)$ showed no difference in HIF-1a stimulation compared to the parental WT GBS (online suppl. Fig. 1). This contrasts with a previous study which detected HIF-1 a production in HeLa-229 and human epidermal keratinocytes [47], although the host cells, GBS strain, and MOI were different than our current study. Additionally, the absence of HIF-1 $1 \alpha$ induction in response to GBS is supported by clinical studies. HIF$1 \alpha$ is elevated in women with preeclampsia $[48,49]$, yet there is a lack of positive association between GBS infection and preeclampsia [50].

Although studies with other bacterial pathogens have demonstrated a protective role for HIF-1 $\alpha$ in reducing pathogen interactions with epithelial cells $[32,51]$, adherence of GBS to vaginal epithelial cell line VK2 was not altered with treatment of AKB-4924 in this study (Fig. 2a). Even so, AKB-4924 did significantly lower production of cytokines IL- $1 \beta$ and IL-8 in GBS-infected VK2s (Fig. 2b, c). Importantly, our assays were conducted under optimized conditions to assess GBS-VK2 interactions based on prior studies $[18,19,37]$, and it remains possible that altering experimental conditions may reveal additional functions of HIF-1 $\alpha$ in this cell line. Our results are in line with previous observations of reduced bladder epithelial cell production of IL-1 $\beta$ and IL-8 upon treatment with AKB-4294 [32]. Similar to our findings (Fig. 2), AKB4924-mediated reduction in cytokine levels was absent in uninfected bladder cells [32]. However, AKB-4924 treatment responses vary among cell types, as AKB-4924 enhanced production of cytokines including IL-8 in the skin epithelial HaCat cell line [44]. HIF-1 $\alpha$ regulation of IL-8 and IL-1 $\beta$ is well-supported [52-54], and thus far, in vivo models testing the impact of HIF- $1 \alpha$ stabilizer AKB-4924 have demonstrated a universal cytokine dampening effect across inflammatory and infection conditions $[32,55$, 56]. Although we observed no impact of AKB-4924 treatment on GBS vaginal colonization over the first 3 days following inoculation in vivo, it remains possible that 
AKB-4924-mediated alterations to vaginal cytokine profiles may impact GBS persistence long term. A recent study described altered vaginal cytokine levels, including IL- $1 \beta$, between mice that cleared GBS compared to those that remained colonized over 3 weeks [57]. We propose that HIF-1a stabilization does not confer protection against GBS colonization. Nevertheless, AKB-4924 dampening of GBS-mediated pro-inflammatory cytokine production by vaginal epithelial cells may serve as a useful strategy for limiting maladaptive pro-inflammatory signaling for other conditions afflicting the female urogenital tract such as bacterial vaginosis and aerobic vaginitis [58-60].

When examining the role of HIF-1 $\alpha$ in immune cell response to GBS, we found no effect of HIF-1 a deficiency on GBS phagocytosis of bone marrow-derived macrophages nor thioglycolate-elicited peritoneal cells (Fig. 3). This result contrasts previous studies demonstrating deficient phagocytosis of closely related group A Streptococcus as well as P. aeruginosa in HIF-1 $\alpha$-deficient BMDMs [42]. HIF-1a deficiency in both professional phagocytes [42] and epithelial cells [61] impedes host control of intracellular bacteria or fungi in a manner linked to blockage of autophagic flux $[61,62]$ or reduction of nitric oxide and cathelicidin levels $[32,42]$. In clear contrast, we observed improved macrophage control of GBS in HIF-1a deficiency (Fig. 3) and worsened control of intracellular GBS in stabilized HIF-1a conditions (Fig. 4). We observed that nonopsonized GBS had decreased survival in HIF-1 $\alpha$-deficient, thioglycolate-elicited cells, which contained a mixture of myeloid cell populations including neutrophils and macrophages. However, we did not further evaluate the specific cells contributing to this phenotype, nor did we assess survival of opsonized GBS in the presence of thioglycolate-elicited cells. Nevertheless, a similar phenomenon is shared with obligate intracellular pathogens, including Leishmania donovani [63] and Toxoplasma gondii [64], both of which demonstrate reduced survival in HIF-1 $\alpha$-deficient cells. BMDM cell viability was similar between HIF-1a-sufficient and HIF$1 \alpha$-deficient cells (online suppl. Fig. 2). Intact BMDM viability suggests that the observed differences in GBS survival may be instead due to altered intracellular trafficking in the absence of HIF-1a. GBS is well-known to persist in macrophages and induce apoptosis [65-67]. However, the role that HIF-1a plays in intracellular localization and trafficking of GBS within the macrophage remains to be determined. We speculate that in the absence of HIF-1 $\alpha$, GBS is trafficked in a manner less conducive to GBS survival. As an example, HIF-1a deficiency in in- testinal epithelial cells enhances survival of adherent invasive E. coli (AIEC) through sequestering AIEC in early autophagic vesicles rather than forming autolysosomes [61]. This hypothesis is supported by a study using J774 macrophages which found that GBS resided in phagosomes and that blocking acidification of these phagosomes/phagolysosomes decreased GBS intracellular survival [68]. The biological interactions of GBS within the macrophage remains an important topic of study. Taken together, these results suggest that loss of HIF-1a may increase the ability of macrophages to control GBS infection in vitro. However, this does not translate to in vivo significance (Fig. 3g) nor does HIF-1 $\alpha$ stabilization impact human neutrophil control of GBS (online suppl. Fig. 3 ). These data lead us to speculate that the in vitro phenomenon of enhanced macrophage control of GBS is ultimately dwarfed by the loss of in vivo immune mechanisms that are HIF-1 $\alpha$ dependent, which could include reactive oxygen and nitrogen species and antimicrobial peptide production and may be cell type and context dependent.

In summary, we conclude that unlike experimental models with other bacterial pathogens, the transcriptional regulator HIF-1 $\alpha$ is not a prominent arm of immune responses to GBS in the context of pathogenesis or commensalism within the host. Due to active research in therapeutic manipulation of HIF-1 $\alpha$ in immune, cancer, and infectious conditions, it is important to note the limitations of this pathway as a target, and to identify the bacterial pathogen exceptions, such as GBS, to this important element of host defense.

\section{Acknowledgements}

We thank the UCSD vivarium staff for breeding and maintaining the mice used in these studies.

\section{Statement of Ethics}

Under approval from UC San Diego IRB protocol 070278X, venous blood was obtained under informed consent from healthy adults. Animal experiments were approved by UC San Diego IACUC, protocol S00227M.

\section{Conflict of Interest Statement}

The authors have no conflicts of interest to declare. 


\section{Funding Sources}

D.v.E. was supported by scholarships from the Hendrik Muller Fund, Nora Baart Foundation, Jo Kolk Foundation, and Fundatie Vrijvrouwe van Renswoude Foundation. J.M.K. was supported by a UC President's postdoctoral fellowship, and K.A.P. was supported by UC Chancellor's and Hartwell Foundation postdoctoral fellowships. Studies were supported by NIH grant U54-HD090259 to V.N. The funders had no role in study design, data collection and analysis, decision to publish, or preparation of the manuscript.

\section{Author Contributions}

G.R.L., D.V.E., J.M.K., and K.A.P. performed experiments. V.N., J.M.K., and K.A.P. conceived and designed experiments, and analyzed and interpreted results. G.R.L., V.M., and K.A.P. drafted the manuscript. All authors contributed to the discussion and edited the manuscript.

\section{References}

1 Seale AC, Bianchi-Jassir F, Russell NJ, KohliLynch M, Tann CJ, Hall J, et al. Estimates of the burden of group B streptococcal disease worldwide for pregnant women, stillbirths, and children. Clin Infect Dis. 2017;65(Suppl 1_2):S200-19.

2 Patras KA, Nizet V. Group B streptococcal maternal colonization and neonatal disease: molecular mechanisms and preventative approaches. Front Pediatr. 2018;6:27.

3 Shabayek S, Spellerberg B. Group B streptococcal colonization, molecular characteristics, and epidemiology. Front Microbiol. 2018;9:437.

4 Raabe VN, Shane AL. Group B streptococcus (Streptococcus agalactiae). Microbiol Spectr. 2019;7(2)

5 Libster R, Edwards KM, Levent F, Edwards MS, Rench MA, Castagnini LA, et al. Longterm outcomes of group B streptococcal meningitis. Pediatrics. 2012;130(1):e8-15.

6 Kohli-Lynch M, Russell NJ, Seale AC, Dangor Z, Tann CJ, Baker CJ, et al. Neurodevelopmental impairment in children after group B streptococcal disease worldwide: systematic review and meta-analyses. Clin Infect Dis. 2017;65(Suppl 1_2):S190-9.

7 Zimmermann P, Curtis N. Effect of intrapartum antibiotics on the intestinal microbiota of infants: a systematic review. Arch Dis Child Fetal Neonatal Ed. 2020;105(2):201-8.

8 Corvaglia L, Tonti G, Martini S, Aceti A, Mazzola G, Aloisio I, et al. Influence of intrapartum antibiotic prophylaxis for group B streptococcus on gut microbiota in the first month of life. J Pediatr Gastroenterol Nutr. 2016; 62(2):304-8.

9 Kwak DJ, Augustine NH, Borges WG, Joyner JL, Green WF, Hill HR. Intracellular and extracellular cytokine production by human mixed mononuclear cells in response to group B streptococci. Infect Immun. 2000; 68(1):320-7.

10 Asplin IR, Carl DJ, Way SS, Jones AL. Role of toll-like receptor 2 in innate resistance to group B streptococcus. Microb Pathog. 2008; 44(1):43-51.

11 von Hunolstein C, Totolian A, Alfarone G, Mancuso G, Cusumano V, Teti G, et al. Soluble antigens from group $B$ streptococci induce cytokine production in human blood cultures. Infect Immun. 1997;65(10):4017-21.

12 Biondo C, Mancuso G, Midiri A, Signorino G, Domina M, Lanza Cariccio V, et al. Essential role of interleukin-1 signaling in host defenses against group B streptococcus. mBio. 2014; 5(5):e01428-14.

13 Harada A, Sekido N, Akahoshi T, Wada T, Mukaida N, Matsushima K. Essential involvement of interleukin-8 (IL-8) in acute inflammation. J Leukoc Biol. 1994;56(5):559-64.

14 Mohammadi N, Midiri A, Mancuso G, Patanè F, Venza M, Venza I, et al. Neutrophils directly recognize group $\mathrm{B}$ streptococci and contribute to Interleukin- $1 \beta$ production during infection. PLoS One. 2016;11(8): e0160249.

15 Mitchell K, Brou L, Bhat G, Drobek CO, Kramer M, Hill A, et al. Group B streptococcus colonization and higher maternal IL-1 $\beta$ concentrations are associated with early term births. J Matern Fetal Neonatal Med. 2013; 26(1):56-61.

16 Nakstad B, Sonerud T, Solevåg AL. Early detection of neonatal group B streptococcus sepsis and the possible diagnostic utility of IL6 , IL-8, and CD11b in a human umbilical cord blood in vitro model. Infect Drug Resist. 2016; 9:171-9.

17 Carey AJ, Tan CK, Mirza S, Irving-Rodgers H, Webb RI, Lam A, et al. Infection and cellular defense dynamics in a novel $17 \beta$-estradiol murine model of chronic human group $B$ streptococcus genital tract colonization reveal a role for hemolysin in persistence and neutrophil accumulation. J Immunol. 2014; 192(4):1718-31.

18 Patras KA, Rösler B, Thoman ML, Doran KS. Characterization of host immunity during persistent vaginal colonization by group $\mathrm{B}$ streptococcus. Mucosal Immunol. 2015;8(6): 1339-48.

19 Patras KA, Wang NY, Fletcher EM, Cavaco CK, Jimenez A, Garg M, et al. Group B streptococcus CovR regulation modulates host immune signalling pathways to promote vaginal colonization. Cell Microbiol. 2013;15(7): 1154-67.

20 Ashford KB, Chavan N, Ebersole JL, Wiggins AT, Sharma S, McCubbin A, et al. Patterns of systemic and cervicovaginal fluid inflammatory cytokines throughout pregnancy. Am J Perinatol. 2018;35(5):455-62.

21 Palazon A, Goldrath AW, Nizet V, Johnson RS. HIF transcription factors, inflammation, and immunity. Immunity. 2014;41(4):51828.

22 Kim KS, Rajagopal V, Gonsalves C, Johnson C, Kalra VK. A novel role of hypoxia-inducible factor in cobalt chloride- and hypoxiamediated expression of IL-8 chemokine in human endothelial cells. J Immunol. 2006; 177(10):7211-24.

23 Fang HY, Hughes R, Murdoch C, Coffelt SB, Biswas SK, Harris AL, et al. Hypoxia-inducible factors 1 and 2 are important transcriptional effectors in primary macrophages experiencing hypoxia. Blood. 2009;114(4):84459.

24 Takeda N, O’Dea EL, Doedens A, Kim JW, Weidemann A, Stockmann C, et al. Differential activation and antagonistic function of HIF- $\{$ alpha $\}$ isoforms in macrophages are essential for NO homeostasis. Genes Dev. 2010; 24(5):491-501.

25 Cramer T, Yamanishi Y, Clausen BE, Förster I, Pawlinski R, Mackman N, et al. HIF-1alpha is essential for myeloid cell-mediated inflammation. Cell. 2003;112(5):645-57.

26 Jantsch J, Chakravortty D, Turza N, Prechtel AT, Buchholz B, Gerlach RG, et al. Hypoxia and hypoxia-inducible factor-1 alpha modulate lipopolysaccharide-induced dendritic cell activation and function. J Immunol. 2008; 180(7):4697-705.

27 McNamee EN, Korns Johnson D, Homann D, Clambey ET. Hypoxia and hypoxia-inducible factors as regulators of $\mathrm{T}$ cell development, differentiation, and function. Immunol Res. 2013;55(1-3):58-70.

28 Shi LZ, Wang R, Huang G, Vogel P, Neale G, Green DR, et al. HIF1alpha-dependent glycolytic pathway orchestrates a metabolic checkpoint for the differentiation of TH17 and Treg cells. J Exp Med. 2011;208(7):1367-76.

29 Blouin CC, Pagé EL, Soucy GM, Richard DE. Hypoxic gene activation by lipopolysaccharide in macrophages: implication of hypoxiainducible factor 1alpha. Blood. 2004;103(3): 1124-30. 
30 Hartmann H, Eltzschig HK, Wurz H, Hantke $\mathrm{K}$, Rakin A, Yazdi AS, et al. Hypoxia-independent activation of HIF-1 by enterobacteriaceae and their siderophores. Gastroenterology. 2008;134(3):756-67.

31 Berger EA, McClellan SA, Vistisen KS, Hazlett LD. HIF-1 $1 \alpha$ is essential for effective PMN bacterial killing, antimicrobial peptide production and apoptosis in Pseudomonas aeruginosa keratitis. PLoS Pathog. 2013;9(7): e1003457.

32 Lin AE, Beasley FC, Olson J, Keller N, Shalwitz RA, Hannan TJ, et al. Role of hypoxia inducible factor-1alpha (HIF-1alpha) in innate defense against uropathogenic Escherichia coli infection. PLoS Pathog. 2015;11 e1004818.

33 Peyssonnaux C, Boutin AT, Zinkernagel AS, Datta V, Nizet V, Johnson RS. Critical role of HIF-1alpha in keratinocyte defense against bacterial infection. J Invest Dermatol. 2008; 128(8):1964-8

34 Okumura CY, Hollands A, Tran DN, Olson J, Dahesh S, von Köckritz-Blickwede M, et al. A new pharmacological agent (AKB-4924) stabilizes hypoxia inducible factor-1 (HIF-1) and increases skin innate defenses against bacterial infection. J Mol Med. 2012;90(9): 1079-89.

35 Pritzlaff CA, Chang JC, Kuo SP, Tamura GS, Rubens CE, Nizet V. Genetic basis for the beta-haemolytic/cytolytic activity of group B streptococcus. Mol Microbiol. 2001;39(2) $236-47$.

36 Patras KA, Ha AD, Rooholfada E, Olson J Ramachandra Rao SP, Lin AE, et al. Augmentation of urinary lactoferrin enhances host innate immune clearance of uropathogenic Escherichia coli. J Innate Immun. 2019;11(6) 481-95.

37 Patras KA, Wescombe PA, Rösler B, Hale JD, Tagg JR, Doran KS. Streptococcus salivarius K12 limits group B streptococcus vaginal colonization. Infect Immun. 2015;83(9):343844.

38 Patras KA, Derieux J, Al-Bassam MM, Adiletta N, Vrbanac A, Lapek JD, et al. Group B streptococcus biofilm regulatory protein A contributes to bacterial physiology and innate immune resistance. J Infect Dis. 2018;218(10): 1641-52.

39 Ryan HE, Poloni M, McNulty W, Elson D, Gassmann M, Arbeit JM, et al. Hypoxia-inducible factor-1alpha is a positive factor in solid tumor growth. Cancer Res. 2000;60(15): 4010-5.

40 Kimmey JM, Huynh JP, Weiss LA, Park S, Kambal A, Debnath J, et al. Unique role for ATG5 in neutrophil-mediated immunopathology during M. tuberculosis infection. Nature. 2015;528(7583):565-9.

41 Patras KA, Doran KS. A Murine model of group B streptococcus vaginal colonization. J Vis Exp. 2016;(117):54708

42 Peyssonnaux C, Datta V, Cramer T, Doedens A, Theodorakis EA, Gallo RL, et al. HIF-1alpha expression regulates the bactericidal ca- pacity of phagocytes. J Clin Invest. 2005; 115(7):1806-15.

43 Polke M, Seiler F, Lepper PM, Kamyschnikow A, Langer F, Monz D, et al. Hypoxia and the hypoxia-regulated transcription factor HIFla suppress the host defence of airway epithelial cells. Innate Immun. 2017;23(4):373-80.

44 Leire E, Olson J, Isaacs H, Nizet V, Hollands A. Role of hypoxia inducible factor-1 in keratinocyte inflammatory response and neutrophil recruitment. J Inflamm. 2013;10(1):28.

45 Jakus IA, Jakus D, Aračić N, Stipić I, Vilović K. Immunohistochemical expression of hypoxia-inducible factor- $1 \alpha$ in stromal cells of vaginal tissue in post-menopausal women with pelvic organ prolapse. Indian J Med Res. 2017;146:S63-7.

46 Depoix CL, de Selliers I, Hubinont C, Debieve F. HIF1A and EPAS1 potentiate hypoxia-induced upregulation of inhibin alpha chain expression in human term cytotrophoblasts in vitro. Mol Hum Reprod. 2017;23(3):199-209.

47 Werth N, Beerlage C, Rosenberger C, Yazdi AS, Edelmann M, Amr A, et al. Activation of hypoxia inducible factor 1 is a general phenomenon in infections with human pathogens. PLoS One. 2010;5(7):e11576.

48 Akhilesh M, Mahalingam V, Nalliah S, Ali RM, Ganesalingam M, Haleagrahara N. Hypoxia-inducible factor- $1 \alpha$ as a predictive marker in pre-eclampsia. Biomed Rep. 2013; 1(2):257-8

$49 \mathrm{Tal} \mathrm{R}$. The role of hypoxia and hypoxia-in ducible factor-1alpha in preeclampsia pathogenesis. Biol Reprod. 2012;87(6):134.

50 Mulla ZD, Carrillo T, Kalamegham R, Hernandez LL, Portugal E, Nuwayhid BS. Is maternal colonization with group B streptococci a risk factor for preeclampsia? J Reprod Med. 2015;60(3-4):117-26.

51 Grigg J, Miyashita L, Suri R. Pneumococcal infection of respiratory cells exposed to welding fumes; Role of oxidative stress and HIF-1 alpha. PLoS One. 2017;12(3):e0173569.

52 Bandarra D, Biddlestone J, Mudie S, Müller $\mathrm{HA}$, Rocha S. HIF-1a restricts NF-kBdependent gene expression to control innate immunity signals. Dis Model Mech. 2015; 8(2):169-81.

53 Tannahill GM, Curtis AM, Adamik J, Palsson-McDermott EM, McGettrick AF, Goel G, et al. Succinate is an inflammatory signal that induces IL- $1 \beta$ through HIF- $1 \alpha$. Nature. 2013; 496(7444):238-42.

54 Palsson-McDermott EM, Curtis AM, Goe G, Lauterbach MA, Sheedy FJ, Gleeson LE, et al. Pyruvate kinase M2 regulates Hif-1a activity and IL- $1 \beta$ induction and is a critical determinant of the warburg effect in LPSactivated macrophages. Cell Metab. 2015; 21(1):65-80

55 Keely S, Campbell EL, Baird AW, Hansbro PM, Shalwitz RA, Kotsakis A, et al. Contribution of epithelial innate immunity to systemic protection afforded by prolyl hydroxylase inhibition in murine colitis. Mucosal Immunol. 2014;7(1):114-23.
56 Campbell EL, Bruyninckx WJ, Kelly CJ, Glover LE, McNamee EN, Bowers BE, et al. Transmigrating neutrophils shape the mucosal microenvironment through localized oxygen depletion to influence resolution of inflammation. Immunity. 2014;40(1):66-77.

57 Sweeney EL, Gardiner S, Tickner J, Trim L, Beagley KW, Carey AJ. Group B streptococcus serotypes Ia and V induce differential vaginal immune responses that may contribute to long term colonization of the female reproductive tract. Am J Reprod Immunol. 2020; 83(1):e13199.

58 Basso B, Giménez F, López C. IL-1beta, IL-6 and IL-8 levels in gyneco-obstetric infections. Infect Dis Obstet Gynecol. 2005;13(4):20711.

59 Hemalatha R, Ramalaxmi BA, KrishnaSwetha G, Kumar PU, Rao DM, Balakrishna N, et al Cervicovaginal inflammatory cytokines and sphingomyelinase in women with and without bacterial vaginosis. Am J Med Sci. 2012 344(1):35-9.

60 Marconi C, Donders GG, Bellen G, Brown DR, Parada CM, Silva MG. Sialidase activity in aerobic vaginitis is equal to levels during bacterial vaginosis. Eur J Obstet Gynecol Reprod Biol. 2013;167(2):205-9.

61 Mimouna S, Bazin M, Mograbi B, DarfeuilleMichaud A, Brest P, Hofman P, et al. HIF1A regulates xenophagic degradation of adherent and invasive Escherichia coli (AIEC). Autophagy. 2014;10(12):2333-45.

62 Friedrich D, Zapf D, Lohse B, Fecher RA, Deepe GS Jr, Rupp J. The HIF-1 $\alpha /$ LC3-II axis impacts fungal immunity in human macrophages. Infect Immun. 2019;87(7).

63 Singh AK, Mukhopadhyay C, Biswas S, Singh VK, Mukhopadhyay CK. Intracellular pathogen leishmania donovani activates hypoxia inducible factor- 1 by dual mechanism for survival advantage within macrophage. PLoS One. 2012;7(6):e38489.

64 Spear W, Chan D, Coppens I, Johnson RS, Giaccia A, Blader IJ. The host cell transcription factor hypoxia-inducible factor 1 is required for Toxoplasma gondii growth and survival at physiological oxygen levels. Cell Microbiol. 2006;8(2):339-52.

65 Cornacchione P, Scaringi L, Fettucciari K, Rosati E, Sabatini R, Orefici G, et al. Group B streptococci persist inside macrophages. Immunology. 1998;93(1):86-95.

66 Valentin-Weigand P, Benkel P, Rohde M, Chhatwal GS. Entry and intracellular survival of group B streptococci in J774 macrophages. Infect Immun. 1996;64(7):2467-73.

67 Fettucciari K, Rosati E, Scaringi L, Cornacchione P, Migliorati G, Sabatini R, et al Group B streptococcus induces apoptosis in macrophages. J Immunol. 2000;165(7):392333.

68 Cumley NJ, Smith LM, Anthony M, May RC. The CovS/CovR acid response regulator is required for intracellular survival of group B streptococcus in macrophages. Infect Immun. 2012;80(5):1650-61. 